\title{
Constipación crónica. Conceptos actuales desde la fisiopatología hasta el tratamiento
}

\author{
Karla Rocío García-Zermeño, José María Remes-Troche \\ Laboratorio de Fisiología Digestiva y Motilidad Gastrointestinal. Instituto de Investigaciones Médico-Biológicas, Universidad Veracruzana. \\ Veracruz, Veracruz, México.
}

Acta Gastroenterol Latinoam 2021;51(1):14-28

Recibido: 09/02/2021 / Aceptado: 10/02/2021 / Publicado online: 22/03/2021 / https://doi.org/10.52787/zrrj9030

\section{Resumen}

La constipación o estreñimiento crónico es una de las patologias gastrointestinales más frecuentes a nivel mundial, y tiene un impacto negativo en la calidad de vida de los pacientes. El objetivo de esta revisión narrativa es presentar la información más novedosa y relevante en relación con el estreñimiento crónico, desde su fisiopatología hasta el tratamiento. Se reconocen al menos tres subtipos de estreñimiento crónico primario: el funcional, el asociado al intestino irritable y el relacionado con los trastornos evacuatorios. Y existen múltiples causas de estreñimiento crónico secundario, en especial algunos fármacos; se detalla en particular la entidad denominada estreñimiento inducido por opioides. Los mecanismos fisiopatológicos del estreñimiento crónico funcional son múltiples (incluyen alteraciones motoras, sensitivas, disbiosis $y$ alteraciones estructurales y funcionales del piso pélvico) y frecuentemente se sobreponen. Ninguna prueba proporciona una descripción completa de la defecación, por lo que en general se emplea una combinación de estas para evaluar

Correspondencia: José María Remes-Troche

Laboratorio de Fisiologia Digestiva y Motilidad Gastrointestinal, Instituto de Investigaciones Médico-Biológicas. Iturbide SN, Colonia Flores Magón (C.P. 91400). Veracruz, Veracruz, México

Correo electrónico: jose.remes.troche@gmail.com / joremes@uv.mx la estructura y las funciones motora y sensorial. Los estudios diagnósticos avanzados de la función del colon, recto y ano son recomendados en pacientes con estreñimiento crónico y en quienes han fallado los tratamientos de primera linea. Con respecto al tratamiento se detalla la utilidad de las medidas higiénico-dietéticas, el ejercicio, la fibra, los laxantes, los nuevos fármacos (como prucaloprida, lubiprostona, linaclotida, plecanatida), la terapia de biorretroalimentación, los probióticos y otras terapias tales como el trasplante de microbiota fecal y la cirugía.

Palabras claves. Estreñimiento, constipación, evacuación, laxantes, fibra, secretagogos.

\section{Chronic Constipation. Current Concepts from Pathophysiology to Treatment}

\section{Summary}

Chronic constipation is one of the most frequent gastrointestinal pathologies worldwide, and it negatively impacts the quality of life of patients. The objective of this narrative review is to present the most innovative and relevant information in relation to chronic constipation, from its pathophysiology to treatment. It is recognized that there are at least three subtypes of primary chronic constipation that are functional, that associated with irritable bowel and that related to evacuation disorders. It is considered that there are multiple causes of secondary chronic constipation, especially drugs and the entity called opioid-induced constipation is specifically detailed. The pathophysiological mechanisms of functional chronic constipation are multiple (they include motor and sensory alterations, dysbiosis, and structural and functional alterations of the pelvic floor) and frequently over- 
lap. No test provides a complete description of defecation; therefore in general, a combination of these is generally used to assess motor and sensory structure and function. Advanced diagnostic studies of the function of the colon, rectum, and anus are recommended in patients with chronic constipation in whom the first-line treatment have failed. Regarding treatment, the usefulness of hygienic-dietary measures, exercise, fiber, the laxatives, the new drugs (such as prucalopride, lubiprostone, linaclotide, plecanatide), biofeedback therapy, probiotics, and other therapies fecal microbiota transplantation and surgery.

Keywords. Constipation, evacuation, laxatives, fiber, secretagogues.

\section{Abreviaturas}

CC: Constipación crónica.

EC: Estreñimiento crónico.

EIO: Estreñimiento inducido por opioides.

HR: Hiposensibilidad rectal.

TE: Trastornos de la evacuación.

AGCC: Ácidos grasos de cadena corta.

ES: Esclerosis sistémica.

SED: Sindrome de Ehlers-Danlos.

EP: Enfermedad de Parkinson.

IF: Incontinencia fecal.

EB: Escala de Bristol.

SII: Sindrome de intestino irritable.

IRM: Resonancia magnética.

PEB: Prueba de expulsión del balón.

ECC: Ensayos clínicos controlados.

PEG: Polietilenglicol.

NNT: Número necesario a tratar.

\section{Introducción}

La "constipación” o estreñimiento crónico (CC o EC) es una de las patologías gastrointestinales más frecuentes a nivel mundial, y tiene un impacto negativo en la calidad de vida de los pacientes. ${ }^{1}$ La prevalencia de EC puede variar de acuerdo con la etnia, el estilo de vida, la dieta, el uso de fármacos y los factores genéticos. La prevalencia media en adultos en la población general es del 16\% y hasta $33,5 \%$ en adultos mayores. ${ }^{2}$ La revisión sistemática y metaanálisis más reciente, que incorpora 45 estudios de la población general, informó una prevalencia global del $14 \% .^{3}$ De acuerdo con el reciente estudio epidemiológico global de la fundación de Roma (realizado en 33 países de los seis continentes) la prevalencia global de EC "funcional" (véase más adelante) varió entre 6,6\% (encuesta cara a cara) y $11,7 \%$ (encuesta por internet), lo que lo posiciona como el trastorno funcional digestivo más frecuente a nivel mundial. ${ }^{4}$ Algunos otros estudios epidemiológicos han demostrado que un consumo bajo de fibra y de agua $(<1,882 \mathrm{ml}$ al día) son factores asociados a estreñimiento. ${ }^{5}$ Si bien la evidencia es más limitada e incluso existen resultados controversiales, algunos estudios han mostrado que el estreñimiento se asocia al sedentarismo (razón de momios (RM) 1,25 , IC 95\% 1,17-1,34) y a la actividad física insuficiente (RM 1,26, IC 95\% 1,16-1,36). ${ }^{6-8}$

\section{Clasificación}

El estreñimiento se define como la defecación no satisfactoria (sensación de evacuación incompleta), resultante de evacuaciones poco frecuentes, o con dificultad de expulsión (sensación de obstrucción anorrectal y necesidad de maniobras manuales para facilitar la evacuación), o ambas. ' Sin embargo, este término también es utilizado para describir una variedad de síntomas, que incluyen heces duras, esfuerzo excesivo, distensión y dolor abdominal. ${ }^{10}$

Según su tiempo de presentación el estreñimiento puede considerarse de inicio "agudo" cuando tiene una evolución menor a una semana y "crónico" cuando los síntomas persisten por más de cuatro semanas. ${ }^{1,8,9} \mathrm{De}$ acuerdo con su origen el EC puede ser primario o secundario. ${ }^{1,8}$ El estreñimiento "primario" es consecuencia de múltiples alteraciones fisiopatológicas (véase la siguiente sección), siendo las más importantes la alteración de la regulación colónica del movimiento de las heces, junto con la falta de coordinación del aparato neuromuscular anorrectal y la disfunción del eje cerebro-intestino. ${ }^{11}$ Mientras que el secundario es causado por múltiples causas, tales como fármacos (opioides, bloqueadores de los canales de calcio, AINEs), trastornos neurológicos (enfermedad de Parkinson), o enfermedades metabólicas (diabetes, hipotiroidismo) e incluso problemas anatómicos (enfermedades anorrectales y colónicas).

En la Tabla 1 se listan una serie de enfermedades y medicamentos que pueden ocasionar EC secundario. Mención especial merece el estreñimiento inducido por opioides (EIO), una entidad descripta recientemente que hace alusión a la causalidad que existe entre el uso de estos fármacos y la aparición o exacerbación de EC. ${ }^{12}$ En la actualidad se estima que el 5\% de los adultos en los Estados Unidos están siendo tratados con opiáceos durante más de tres meses por causas no relacionadas con el cáncer; de este grupo entre el 40\% y 90\% experimentan síntomas de EC. ${ }^{13,14} \mathrm{El}$ EIO, de acuerdo con los criterios de Roma IV, es un término que se utiliza para describir a aquellos pacientes cuyos síntomas de estreñimiento apa- 
recen o empeoran cuando inician, cambian o aumentan el consumo de opioides. ${ }^{8}$ Es muy importante mencionar que esta entidad es susceptible de tratamiento con medicamentos específicos como el alvimopan, el naloxegol y la metilnaltrexona.

Tabla 1. Causas secundarias de estreñimiento

\begin{tabular}{|c|c|}
\hline Medicamentos & Trastornos metabólicos \\
\hline • Analgésicos (opiáceos) & - Diabetes mellitus \\
\hline - Anticolinérgicos & - Hipotiroidismo \\
\hline - Antiespasmódicos & - Hipercalcemia \\
\hline - Antipsicóticos & - Hipokalemia \\
\hline - Antiparkinsonianos & • Hipomagnesemia \\
\hline - Antidepresivos tricíclicos & - Uremia \\
\hline - Anticonvulsivos & - Porfiria \\
\hline - Antiácidos que contienen aluminio & - Intoxicación por metales \\
\hline - Antihipertensivos & pesados \\
\hline - Calcioantagonistas & • Panhipopituitarismo \\
\hline - Alfa metildopa & \\
\hline - Suplementos de hierro y calcio & \\
\hline - Diuréticos & \\
\hline Trastornos anorectales y colónicos & Trastornos psiquiátricos \\
\hline • Enfermedad hemorroidal & - Trastornos de la alimentación \\
\hline - Diverticulitis & • Depresión \\
\hline - Proctitis posrradiación & - Trastornos de somatización \\
\hline • Neoplasias malignas & \\
\hline Trastornos neurológicos & Otras \\
\hline • Esclerosis múltiple & - Miopatías \\
\hline - Lesiones medulares & - Amiloidosis \\
\hline - Enfermedad de Parkinson & - Escleroderma \\
\hline - Enfermedad vascular cerebral & - Trastornos cognitivos \\
\hline & - Inmovilidad prolongada \\
\hline
\end{tabular}

\section{Fisiopatología}

El EC debe considerarse como una enfermedad compleja y multifactorial. Es importante recordar que el acto de la defecación es complejo, y que involucra estructuras neuromusculares que deben coordinarse, además de que esta influenciado por el contenido de agua y el volumen de las heces, la ingesta calórica, la microbiota intestinal y los trastornos psicológicos y conductuales. ${ }^{1,9}$ En la Figura 1 se ilustran los principales mecanismos fisiopatológicos asociados al EC.

a) Disfunción motora: Se han descripto múltiples alteraciones en la motilidad y la capacidad contráctil del colon, que condicionan un EC por "tránsito lento" que se caracteriza por un retraso del movimiento del contenido intraluminal a través del colon ascendente y transverso. ${ }^{1,8,9}$ En cuanto a la contractilidad colónica, se ha descripto una disminución en el número de las contracciones colónicas propagadas de alta amplitud, ${ }^{15,16}$ un aumento no coordinado de la actividad motora del colon distal, ${ }^{17}$ y anomalías en los circuitos peristálticos debido a alteraciones del control neural parasimpático extrínseco o entérico. ${ }^{18-20}$ Un estudio reciente por Zikos et al. ${ }^{21}$ mostró que en pacientes que reportaban sobreposición de los síntomas de dispepsia y estreñimiento, los diagnosticados con estreñimiento con transito lento tenían significativamente más probabilidades de tener también retraso en el vaciamiento gástrico, en comparación con aquellos con estreñimiento con tránsito normal.

b) Disfunción sensitiva: La hiposensibilidad rectal (HR) se relaciona con una percepción atenuada o disminuida de la distensión rectal, la cual puede explicarse porque algunos pacientes no experimentan la sensación del deseo de defecar. ${ }^{22}$ Los estudios observacionales han reportado HR hasta en el $60 \%$ de los pacientes con estreñimiento. La etiología es incierta, pero se han propuesto varios mecanismos. En algunos pacientes, en los que existe una alteración de la vía aferente (por ejemplo debido al daño del nervio pélvico o una lesión de la médula espinal), existe una clara relación causa-efecto con el desarrollo de HR. Se ha reportado que hasta el 78\% de los pacientes con lesión completa de la médula espinal y disfunción del intestino grueso y el $43 \%$ de los individuos con lesiones incompletas tienen disminución de la sensibilidad rectal. ${ }^{23-25}$

c) Trastornos de la evacuación: La evacuación de las heces requiere de la coordinación entre el esfuerzo y la relajación de los músculos del piso pélvico y los esfínteres anales (Figura 2). Los trastornos de la evacuación (TE) constituyen el segundo tipo más común de EC y es un término utilizado para describir las características clínicas y/o de laboratorio relacionadas con la incapacidad para expulsar las heces de manera satisfactoria. ${ }^{1,12,26}$ Otros términos utilizados para describir estas alteraciones son "anismo", "disinergia defecatoria" u "obstrucción defecatoria funcional". ${ }^{27,28}$ Los pacientes con TE presentan incapacidad para coordinar los músculos de la pared abdominal, rectoanal y piso pélvico durante la defecación debido a la alteración de la fuerza de propulsión rectal (inadecuada propulsión) y/o abdominal, la alteración en la relajación anal o el aumento de la resistencia de salida anal debido a la contracción del esfínter anal externo o puborrectal (defecación disinérgica). ${ }^{29,} 30$ Clínicamente, la mayoría de los pacientes con EC se quejan de síntomas sugestivos de TE, siendo el esfuerzo excesivo el síntoma más reportado. 
Figura 1. Mecanismos fisiopatológicos relacionados con el estreñimiento crónico primario

Alteraciones motoras

- Disminución de ondas de alta amplitud

- Incoordinación proximal-distal

- Disminución de sustancia P

- Disminución de células de Cajal

- Alteraciones de la colágena

Alteraciones sensitivas

- Hiposensibilidad rectal

- Alteraciones aferentes/esferentes

- Distensibilidad rectal anormal
- Hiposensibilidad

- Trastornos piscológicos

- Enfermedad de Parkinson

\section{)}<smiles>[LiH]</smiles>



Cotras

- Alteraciones genéticas

- Enfermedad del tejido conectivo

- Esclerosis

- Ehlers-Danlos

Disbiosis

- Disminución de lactobacilos

- Disminución de bacteroidetes

- Aumento de clostridiales

- Aumento de enterobacterias

- Alteraciones en metaboloma

Trastornos evacuatorios funcionales

- Propulsión inadecuada

- Contracción inapropiada

- Ausencia de relajación

Trastornos evacuatorios estructurales

- Rectocele

- Intususcepción

- Enterocele

Figura 2. Mecanismos fisiopatológicos relacionados con trastornos evacuatorios y su representación topográfica mediante manometría de alta resolución

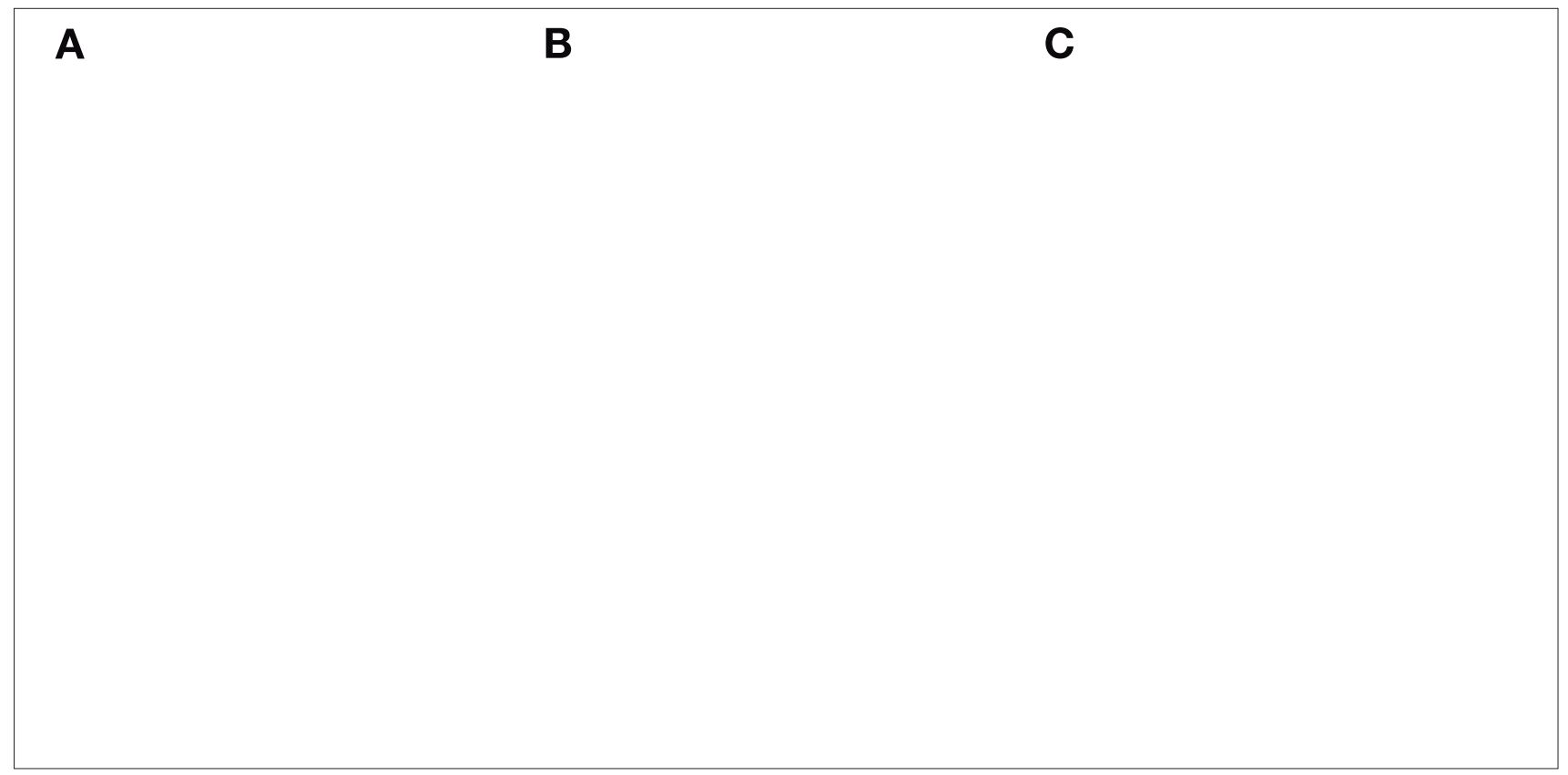

Nota: La figura A ilustra la sincronía o sinergia entre el aumento de la presión intrarrectal (\#1) y la relajación de forma simultánea de la cintilla puborrectal (\#2) y los esfinteres anales (interno [EAl] y externo [EAE] \#3), facilitando así la expulsión de las heces. En la figura B, se muestra cómo la ausencia de un pujo adecuado (\#1) no es capaz de generar un gradiente de presión suficiente para que la cintilla puborrectal y los esfínteres se relajen apropiadamente (\#2 y \#3), condicionando así un trastorno evacuatorio. La figura C ilustra cómo, a pesar de que existe un pujo adecuado (\#1), la ausencia de relajación o la contracción inapropiada del puborrectal y los esfínteres (\#2 y \#3) impide la evacuación de las heces (defecación disinérgica). 
Los principales mecanismos fisiopatológicos responsables se consideran fenómenos obstructivos estructurales, como por ejemplo la intususcepción rectal de alto grado, el rectocele o el enterocele, que impiden la expulsión de las heces. ${ }^{27,30}$ Estas alteraciones estructurales se pueden sobreponer con alteraciones funcionales como la $\mathrm{HR}$, que disminuye el deseo de evacuación, y fomentan conductas como el pujo excesivo sobre un piso pélvico débil. ${ }^{27,30}$ Además, se ha descripto que aproximadamente el $7 \%$ de los pacientes con TE tendrán megarrecto relacionado a la disminución o ausencia de la sensación de llenado rectal. ${ }^{23,31}$

d) Disbiosis: Al igual que en otros trastornos funcionales digestivos, en los últimos años se ha observado que existe evidencia que sugiere que la disbiosis puede tener un papel determinante en algunos pacientes con EC. En general, los estudios en adultos informan menos diversidad y abundancia de bifidobacterias y lactobacilos, aunque estos hallazgos no se demuestran de manera consistente en pacientes pediátricos. ${ }^{32}$ También se ha descripto un aumento significativo a nivel de los Clostridiales (específicamente de C. sporogenes, C. paraputrificum, C. fallax, y C. Innocuum), así como de Enterobacteriaceae (como Escherichia coli y Staphylococcus aureus). ${ }^{33,34}$ Además, se han descripto alteraciones en el metaboloma, en especial, diferencias en los ácidos grasos de cadena corta (AGCC). ${ }^{35} \mathrm{Al}$ parecer, un tránisto colónico lento disminuye los AGCC en las heces, ya que su absorción se incrementa. Una evidencia más es el hecho de que algunos estudios han demostrado mediante la prueba del aliento un incremento en la producción de metano en pacientes con EC con tránsito colónico lento, aunque no se ha demostrado que exista una correlación entre la producción de metano y la gravedad de los síntomas de estreñimiento. ${ }^{36,37}$ La mayoría de estos estudios son de casos y controles, por lo que es difícil establecer si estas diferencias son una causa o simplemente una consecuencia del estreñimiento.

e) Alteraciones del tejido conectivo: Recientemente la asociación entre EC y enfermedades del tejido conectivo ha llamado mucho la atención, a partir del hecho de que hasta el $50 \%$ de los pacientes con esclerosis sistémica (ES) o síndrome de Ehlers-Danlos (SED) padecen de estreñimiento. ${ }^{38,39}$ Los síntomas de TE son muy comunes y hay una alta prevalencia de HR, defecación disinérgica y anomalías morfológicas rectales. ${ }^{40}$

f) Otros mecanismos relacionados: Desde la década de 1960 se ha reportado en la literatura que el EC específicamente con tránsito lento podría producirse como resultado de una neuropatía entérica, y esto podría ser determinado genéticamente. Esta hipótesis se basa sobre todo en observaciones clínicas de sintomatología de inicio temprano y antecedentes familiares positivos. Sin embargo, hoy no existe evidencia de esta posible asociación. ${ }^{41}$

Tradicionalmente la enfermedad de Parkinson (EP) se considera un trastorno motor que resulta de la pérdida de neuronas dopaminérgicas en la pars compacta de la sustancia negra. Sin embargo, varios estudios describen que pueden existir alteraciones "prodrómicas" no motoras que afectan la calidad de vida de los pacientes que luego desarrollan la EP. Estas disfunciones prodrómicas comprenden una amplia gama de trastornos de la motilidad gastrointestinal, que incluyen disfagia, retraso del vaciamiento gástrico y EC. ${ }^{42}$ Se ha descripto que los hallazgos histológicos patognómonicos de la EP, los agregados de $\alpha$-sinucleína que forman los cuerpos de Lewy, están presentes en el sistema nervioso entérico antes del diagnóstico clínico, lo que sugiere que el tracto gastrointestinal y su conexión neural (vagal) con el sistema nervioso central podría tener un papel importante en la etiología de la enfermedad.

$\mathrm{Al}$ contrario de lo que se piensa, la coexistencia entre EC e incontinencia fecal (IF) es muy alta (hasta el 69\%). ${ }^{1}$ La fisiopatología de esta sobreposición es indudablemente multifactorial, y ambas entidades tienen mecanismos subyacentes en común. Swash et al. propusieron una hipótesis unificadora para los trastornos del piso pélvico (incluido el estreñimiento) y la IF, donde la lesión obstétrica (mujeres) o el estreñimiento (hombres y mujeres), caracterizados por un esfuerzo crónico al defecar, conducen a la denervación del piso pélvico y la musculatura del esfínter anal y, en última instancia, a IF. ${ }^{43}$ Otros mecanismos fisiopatológicos importantes incluyen el "rebosamiento" secundario a la impactación, o cuando la IF resulta de una evacuación rectal incompleta ya sea por una causa estructural o por una funcional. Reconocer la sobreposición entre EC e IF tiene implicancias importantes con respecto al manejo. Si la IF es secundaria al estreñimiento subyacente, entonces la intervención dirigida a mejorar los síntomas del estreñimiento debe considerarse el tratamiento de primera línea.

El papel de los factores psicológicos se ha evaluado ampliamente en el contexto del EC. Los eventos traumáticos y el abuso físico y sexual en la niñez se asocian de manera independiente con una mayor incidencia de EC. ${ }^{44}$ El rasgo de personalidad neurótica está particularmente asociado con el estreñimiento. ${ }^{45}$ 


\section{Evaluación clínica}

El abordaje diagnóstico primario debe enfocarse en los síntomas específicos de EC, evaluar medicamentos que pudieran ser su causa, así como excluir enfermedad orgánica y síntomas de alarma. Uno de los pilares más importantes en la valoración del estreñimiento es el examen físico detallado, y en particular un tacto rectal, que tiene una sensibilidad del $75 \%$ y una especificidad del $87 \%$ para detectar TE. ${ }^{46} \mathrm{La}$ inspección perineal puede revelar hemorroides externas o internas prolapsadas, fisuras, cicatrices o excoriaciones cutáneas, así como mostrar la presencia de anomalías estructurales tales como estenosis o espasmos, dolor a la palpación, masas o impactación de heces. ${ }^{47}$ Los cuestionarios de síntomas intestinales son una herramienta rápida y eficaz para evaluar los síntomas del estreñimiento, mientras que un diario intestinal de dos semanas proporciona una evaluación más refinada de las variaciones del día a día y la relación entre la forma de las heces y otros síntomas. ${ }^{1}$ También es importante recopilar información sobre los hábitos intestinales previos, cuándo cambiaron y lo que los pacientes consideran normal, porque las percepciones, influenciadas por las normas sociales y culturales, influyen en la notificación de los síntomas.

Los pictogramas de la forma de las evacuaciones o la Escala de Bristol (EB) es un método que ha sido considerado el instrumento más fidedigno para evaluar el tránsito colónico en comparación con los síntomas. ${ }^{48}$ En un inicio, su función principal fue proveer al clínico y al paciente de una herramienta confiable para esclarecer el tipo de patrón defecatorio (por ej. normal vs. diarrea), haciendo una correlación con el tránsito colónico. ${ }^{49,50}$ Posteriormente, se evaluó para caracterizar el patrón de las evacuaciones, demostrando que era un método reproducible y confiable. ${ }^{51}$ Estos hallazgos permitieron que la EB se propusiera como una herramienta útil para clasificar a los pacientes con SII en subtipos (diarrea, mixto y estreñimiento). ${ }^{12}$ Estudios subsecuentes han correlacionado la EB con el tránsito con marcadores radiopacos y con la cápsula de motilidad inalámbrica para medir la velocidad del tránsito colónico. Se ha observado una buena correlación con el tránsito colónico al compararlo con la cápsula de motilidad inalámbrica $(r=0,79)$ y los marcadores $(r=0,64) .52$

El EC funcional es un síndrome clínico que presenta diferentes síntomas, los cuales se expresan de manera variable en los individuos, de acuerdo con diversos factores, como la localización geográfica, la dieta y la actividad física, entre otros. Los criterios de Roma, actualmente en su versión IV, son los más utilizados para el diagnóstico de EC funcional (Tabla 2). ${ }^{12}$

\section{Tabla 2. Criterios de Roma IV para estreñimiento funcional}

1. Debe presentar dos o más de los siguientes criterios durante los últimos tres meses y haber iniciado los síntomas seis meses antes del diagnóstico:

- $\leq 2$ evacuaciones por semana.

- Esfuerzo en más del 25\% de las evacuaciones (Bristol 1-2).

- Sensación de evacuación incompleta en más del 25\% de las evacuaciones.

- Sensación de obstrucción / bloqueo anorrectal en más del 25\% de las evacuaciones.

- Maniobras manuales para facilitar la evacuación en más del 25\% de las evacuaciones.

2. Criterios insuficientes para síndrome de intestino irritable.

3. Las heces blandas rara vez están presentes sin el uso de laxantes.

Adaptado de la referencia nro. 12.

\section{Pruebas diagnósticas}

Ninguna prueba proporciona una descripción completa de la defecación, por lo que en general se emplea una combinación de estas (Tabla 3) para evaluar la estructura y la funciones motora y sensorial. ${ }^{53}$ Los estudios diagnósticos avanzados de la función del colon, recto y ano son recomendados en pacientes con EC y en quienes han fallado los tratamientos de primera línea como la optimización de la consistencia de las heces, el entrenamiento del hábito intestinal, el asesoramiento sobre el estilo de vida y el tratamiento farmacológico estándar. ${ }^{1,54}$

a) Estudios para valorar el tránsito intestinal: En pacientes con EC y que reportan evacuaciones infrecuentes los estudios de tránsito intestinal pueden ser útiles. Tradicionalmente, los métodos radiológicos para evaluar el transito colónico, como la administración oral de marcadores radiopacos y la centellografía, tienden a enfocarse en la cuantificación del tránsito colónico. Sin embargo, en la actualidad es bien sabido que la alteración en la motilidad no es restringida al colon y, por lo tanto, las nuevas técnicas (capsula de motilidad inalámbrica y tránsito con método 3D) tienen la habilidad de evaluar la función panentérica. ${ }^{1,54}$

1. Marcadores radiopacos: Se considera una prueba de escrutinio y está indicada para diferenciar entre tránsito intestinal normal o lento. ${ }^{54}$ Existen múltiples protocolos para su realización; el más simple implica la ingesta de marcadores (20-50) seguida de la realización de una radiografía simple de abdomen, habitualmente después de 120 horas. ${ }^{54} \mathrm{El}$ transito colónico lento se define si existen $>5(20 \%)$ marcadores retenidos en el día cinco y además puede proporcionar una evaluación cuantitativa segmentaria y total del tránsito colónico. ${ }^{55}$ 
Tabla 3. Pruebas para el diagnóstico del estreñimiento

\begin{tabular}{|c|c|c|c|}
\hline Investigación & $\begin{array}{l}\text { Escrutinio, avanzado } \\
\text { o experimental }\end{array}$ & $\begin{array}{l}\text { Principal información fisiopatológica } \\
\text { que proporciona }\end{array}$ & $\begin{array}{l}\text { Otra información fisiopatológica } \\
\text { que proporciona }\end{array}$ \\
\hline \multicolumn{4}{|l|}{ Pruebas de tránsito intestinal } \\
\hline Marcadores radiopacos & Escrutinio & Retraso en el tránsito intestinal & \\
\hline Centellografia & Avanzado & Retraso en el tránsito intestinal & $\begin{array}{l}\text { Retraso en el tránsito gastrointestinal e } \\
\text { intestinal regional (extensión de la técnica) }\end{array}$ \\
\hline Cápsula motilidad inalámbrica & Avanzado & $\begin{array}{l}\text { Retraso en el tránsito gastrointestinal e } \\
\text { intestinal regional }\end{array}$ & $\begin{array}{l}\text { Dismotilidad gastrointestinal regional; } \\
\text { disbiosis / alteración en la fermentación } \\
\text { colónica }\end{array}$ \\
\hline Cápsula de tránsito 3D & Experimental & $\begin{array}{l}\text { Retraso en el tránsito gastrointestinal e } \\
\text { intestinal regional }\end{array}$ & Dismotilidad gastrointestinal regional \\
\hline
\end{tabular}

Pruebas de contractilidad intestinal

$\begin{array}{llll}\text { Manometría colónica } & \text { Avanzado } & \text { Dismotilidad gastrointestinal regional } & \\ \text { Baróstato colónico } & \text { Avanzado } & \text { Alteración del tono colónico } & \text { Dismotilidad colónica } \\ \text { IRM en tiempo real } & \text { Experimental } & \begin{array}{l}\text { Dismotilidad colónica (alteración del } \\ \text { movimiento de la pared) }\end{array} & \text { Alteraciones en el volumen luminal colónico }\end{array}$

Pruebas de evacuación

$\begin{array}{llll}\begin{array}{l}\text { Manometría anorrectal } \\ \text { Prueba de expulsión de balón }\end{array} & \text { Escrutinio } & \text { Dismotilidad colónica } \\ \text { Eltrasonido transperineal } & \text { Escrutinio } & \begin{array}{l}\text { Coordinación rectoanal anormal; } \\ \text { propulsión rectal pobre; disinergia anal }\end{array} & \text { Disfunción del esfínter anal } \\ \text { Defecografía con bario } & \text { Avanzado } & \begin{array}{l}\text { Alteración de la defecación } \\ \text { Características obstructivas funcionales } \\ \text { y/o estructurales }\end{array} & \\ \text { Defecografía con IRM } & \text { Avanzado } & \text { Alteración de la defecación; características } & \text { Anomalías multicompartimentales (cuando } \\ \text { obstructivas funcionales y/o estructurales } & \text { se opacifican adecuadamente) }\end{array}$

Pruebas de sensibilidad

$\begin{array}{lll}\text { Distensión con balón } & \text { Escrutinio } & \text { Hipo e hipersensibilidad rectal } \\ \text { Baróstato } & \text { Avanzado } & \text { Hipo e hipersensibilidad rectal }\end{array}$

Alteración en la complianza rectal y en la capacidad

IRM: Imágenes por resonancia magnética.

Adaptado de la referencia nro. 9.

2. Centellografía: Este método se considera el "estándar de oro" para la evaluación del tiempo del tránsito colónico. La técnica implica seguir la ingesta de una cápsula de liberación retardada que contiene carbón activado o esferas de poliestirenomarcado radiactivamente con $\mathrm{Tc}^{99}$ o Indio ${ }^{111}$ recubierto por un metacrilato polimérico sensible al $\mathrm{pH}$, que se disuelve a un $\mathrm{pH}$ alcalino dentro del íleon distal, liberando el radioisótopo dentro del colon ascendente. ${ }^{55}$ Se evalúa la progresión del químico marcado a través del tracto gastrointestinal, utilizando una cámara y tomando gammagrafías seriadas. El diagnóstico de retraso del tránsito colónico se determina por la posición del centro geométrico de la masa del isótopo en momentos determinados. ${ }^{55,56}$ La prueba puede extenderse para incluir también la evaluación del tránsito gástrico y del intestino delgado. ${ }^{54-57}$ 
3. Cápsula de motilidad inalámbrica: Son dispositivos en forma de cápsulas ingeribles, las cuales miden la temperatura, el $\mathrm{pH}$ y la presión intraluminal a medida que atraviesan el intestino, y muestran una buena correlación con las pruebas de marcadores radiopacos. Los estudios de cápsulas han demostrado que más de un tercio de los pacientes con EC tiene alteración en el tránsito que se extiende más allá del colon. También pueden medir el tránsito del intestino delgado, el vaciamiento gástrico y la actividad motora del colon. Sin embargo, este estudio toma cinco días y requiere que los pacientes usen un dispositivo de recolección de datos. ${ }^{1,27,54}$

\section{b) Pruebas de motilidad colónica}

1. Manometría colónica: Esta prueba se indica en pacientes seleccionados, ya que se emplea para la investigación avanzada de la motilidad colónica, en especial en pacientes con EC de tránsito lento, refractarios al tratamiento, que están siendo considerados para colectomía. ${ }^{1}$ 27, 54 Generalmente se utiliza para determinar la presencia o ausencia de patrones motores colónicos en respuesta a estímulos fisiológicos y químicos. ${ }^{57} \mathrm{El}$ protocolo más utilizado se realiza después de la evacuación intestinal, colocando un catéter con $>20$ sensores de registro, espaciados entre 10 y $30 \mathrm{~mm}$, con la ayuda de un colonoscopio. La prueba puede realizarse de forma estacionaria o ambulatoria de 24 horas, y ya existen estudios con la tecnología de alta resolución. Sin embargo, debido a un número limitado de estudios en sujetos sanos, falta una definición clara de motilidad colónica "normal".

2. Resonancia magnética: El uso de imágenes por resonancia magnética (IRM) para investigar la motilidad colónica es actualmente experimental, pero permite la visualización directa de la pared del colon o del contenido de la luz. ${ }^{1,27}$ Además, la evaluación del movimiento de la pared colónica puede combinarse con otras medidas de resonancia magnética, por ejemplo tránsito y volumen para proporcionar una vista objetiva del colon, tanto en términos de anatomía como de función. ${ }^{58}$

c) Pruebas para evaluar el mecanismo defecatorio: Estas pruebas son especialmente útiles en pacientes con EC y síntomas de disinergia, y son esenciales para evaluar a los pacientes con TE.

1. Prueba de expulsión del balón: La prueba de expulsión del balón (PEB) es una prueba sencilla y ampliamente disponible para detectar trastornos de la evacuación. El balón desinflado se coloca en el recto y se infla con $50 \mathrm{ml}$ de agua templada, y el paciente registra con un cronómetro el tiempo que tarda la expulsión en la posición sentada. ${ }^{59}$ El valor normal depende de la técnica y, generalmente, es de entre uno y tres minutos. ${ }^{60}$
En el estudio de validación más grande realizado hasta el momento (286 pacientes y 40 controles), Chiarioni y col. ${ }^{60}$ demostraron que esta prueba tiene una alta correlación con la manometría anorrectal y la electromiografía, y que el límite superior normal debe ser de dos minutos. Estos autores recomiendan utilizar una sonda de Foley de $16 \mathrm{Fr}$, llenarla con $50 \mathrm{ml}$ de agua a temperatura ambiente y poner al paciente a defecar en posición sentada. Sin embargo, se han descripto variaciones en la técnica en la posición (decúbito lateral izquierdo o sentado), con o sin tracción, diferentes volúmenes de aire o agua insuflados, $\mathrm{y}$ al momento no existe consenso universal de cómo realizar esta prueba. ${ }^{61} \mathrm{Si}$ bien la prueba es muy sensible y específica para identificar TE, los resultados pueden ser falsos positivos en pacientes con laxitud pélvica, como en más de $90 \%$ de los pacientes con rectocele grande, enterocele, peritoneocele y/o sigmoidocele; por lo tanto, los resultados anormales requieren pruebas adicionales.

2. Defecografía: Este estudio proporciona información sobre la función y la anatomía del anorrecto. Puede realizarse mediante fluoroscopía o resonancia magnética, con una pasta con contraste insertada en el recto para actuar como un sustituto de las heces. ${ }^{1,54}$ Luego se le pide al paciente que evacue esta pasta mientras se muestran imágenes representativas. Pueden identificarse anormalidades anatómicas (por ej. rectocele, enterocele e invaginación intestinal), así como la capacidad para coordinar la musculatura del piso pélvico durante las maniobras de evacuación. ${ }^{1,54}$ La resonancia magnética en particular proporciona una excelente evaluación de todos los compartimentos del piso pélvico, sin la necesidad de radiación. ${ }^{54}$ Sin embargo, existe una variabilidad significativa en las medidas utilizadas para informar los resultados y, además, existe cierta superposición de hallazgos entre sujetos sintomáticos y de control, en especial en mujeres con antecedente de parto.

3. Manometría anorrectal: Es un estudio fisiológico ampliamente disponible y fácil de realizar. Como parte de un protocolo estandarizado recomendado por el Grupo de Trabajo Internacional de Fisiología Anorrectal, se evalúa el tono del esfínter anal en reposo, así como el reflejo rectoanal, la sensibilidad rectal y los cambios de presión durante las maniobras de la defecación, la cual proporciona información sobre la coordinación rectoanal a través de la medición simultánea de las presiones anales y rectales. ${ }^{62}$ Los datos se interpretan tanto cuantitativa como cualitativamente. En conjunto con una prueba para evaluar la defecación (prueba de expulsión de balón o defecografía), los hallazgos tales como patrones anormales de coordinación recto-anal, que se manifiestan como 
una propulsión rectal pobre y/o disinergia anal, se han utilizado para el diagnóstico de defecación disinérgica, reconocida en la nueva Clasificación Internacional de Londres como trastornos menores de la función anorrectal. ${ }^{63}$ La manometría puede realizarse con catéteres de estado sólido o de perfusión y recientemente se ha incorporado la tecnología de alta resolución, tanto en estado sólido como perfusión, que obvian la necesidad de realizar la técnica de extracción por etapas o pull-through, al contar con un mayor número de sensores, además de que permiten una mejor caracterización topográfica de la región anorrectal. ${ }^{63}$ Sin embargo, utilizando esta técnica se ha descripto un mayor número de falsos positivos para TE, probablemente debido a la existencia de más sensores y a la ausencia de parámetros diseñados de manera específica para esta nueva tecnología. ${ }^{64,65}$

4.- Fecobionic: Este es un dispositivo muy novedoso, que es una especie de balón elíptico distensible, de $10 \mathrm{~cm}$ de largo, que simula materia fecal de consistencia Bristol 4 y que tiene varios sensores que evalúan la presión, la orientación y la flexión durante la evacuación. ${ }^{66}$ Combina una evaluación directa del tiempo de evacuación con medidas fisiológicas que detallan la coordinación rectoanal y la sensación rectal. Se encuentra aún en fase experimental y de validación para determinar su utilidad en la práctica clínica.

d) Pruebas para evaluar la sensibilidad: Estas son esenciales en la evaluación diagnóstica integral, ya que las vías sensoriales viscerales intactas son necesarias para la función intestinal normal. La distensión del recto a través de un balón intrarrectal es el método más utilizado para cuantificar la sensibilidad rectal. ${ }^{54} \mathrm{La}$ Clasificación de Londres recomienda la documentación de tres umbrales sensoriales utilizando un protocolo de distensión en rampa o distensión fásica incremental: volumen de la primera sensación constante, volumen del deseo defecatorio y volumen máximo tolerado. ${ }^{63}$ Los umbrales elevados indican hiposensibilidad rectal y los umbrales disminuidos indican hipersensibilidad rectal. Actualmente el estándar de oro para determinar la sensación visceral es el baróstato electromecánico, que es un pistón controlado por computadora conectado a una bolsa distensible con un volumen mayor que la zona de la víscera que se examina. Sin embargo, debido a la disponibilidad restringida, el costo y la duración del procedimiento, tienen un uso limitado en la práctica clínica. ${ }^{54}$

\section{Tratamiento}

El objetivo del tratamiento es corregir las alteraciones intestinales, mejorar los síntomas y la calidad de vida de los pacientes.

Debe plantearse un manejo integral que incluya medidas higiénico-dietéticas, que comprenden: realizar ejercicio (mejora el tránsito intestinal y los síntomas de estreñimiento), ${ }^{67,68}$ adoptar una postura correcta (favorece la apertura del ángulo recto anal) y realizar una maniobra de pujo sin esfuerzo excesivo, ${ }^{70}$ además de aprovechar los momentos de mayor actividad motora del colon (por ej. al despertar o después de la ingesta de alimentos), ${ }^{69}$ y el consumo de 1,5 a 2 litros de agua al día. ${ }^{70}$

a) Fibra: El consumo de fibra, mediante alimentos ricos (ciruela, kiwi, nopal, linaza) en esta o suplementos, puede acelerar el tránsito intestinal, ya que se sabe que el aumento en la formación del bolo estimula la peristalsis colónica. ${ }^{71}$ Además, la retención de líquido que provoca la fibra es útil para disminuir la consistencia y favorecer la evacuación de las heces. ${ }^{72}$

Los efectos terapéuticos potenciales, el bajo costo, el perfil de seguridad y otros posibles beneficios para la salud de la fibra dietética justifican su aumento en la ingesta como tratamiento inicial. La mayoría de las guías disponibles recomiendan una dieta rica en fibra, con una ingesta recomendada de al menos 25-30 g por día. ${ }^{1,9,10}$ Las revisiones sistemáticas respaldan la recomendación de aumentar la ingesta de fibra dietética y, en particular, la fibra soluble (como psyllium o ispaghula) mejora los síntomas en pacientes con EC o SII-C. El metaanálisis más reciente que evaluó siete ensayos clínicos controlados (ECC) demostró que el 77\% de los que recibieron suplementos de fibra respondieron, en comparación con el $44 \%$ de los que recibieron placebo (riesgo relativo $[\mathrm{RR}]$ de éxito de 1,$71 ; p=0,003$ ) y se estima un número necesario a tratar (NNT) de 3 (IC $95 \%$ de 2,6-3,4). ${ }^{73}$ Sin embargo, es muy importante mencionar que en algunos pacientes la fibra dietética o los suplementos pueden agravar los síntomas asociados al estreñimiento, como distensión abdominal y flatulencias, por lo que la dosis recomendada va a depender de la tolerancia de cada paciente.

b) Tratamiento farmacológico: Debido a los efectos del EC sobre la calidad de vida de los individuos que lo padecen, es recomendable utilizar tratamiento farmacológico en aquellos pacientes que han fallado a las medidas higiénico-dietéticas iniciales. Existen múltiples fármacos que han demostrado ser más eficaces que el placebo y el que se elija debe individualizarse sobre la base de la evidencia y la disponibilidad (Figura 3). 
Figura 3. Clasificación de la calidad de la evidencia y de la fuerza de las recomendaciones de acuerdo con el sistema GRADE para el tratamiento del estreñimiento crónico

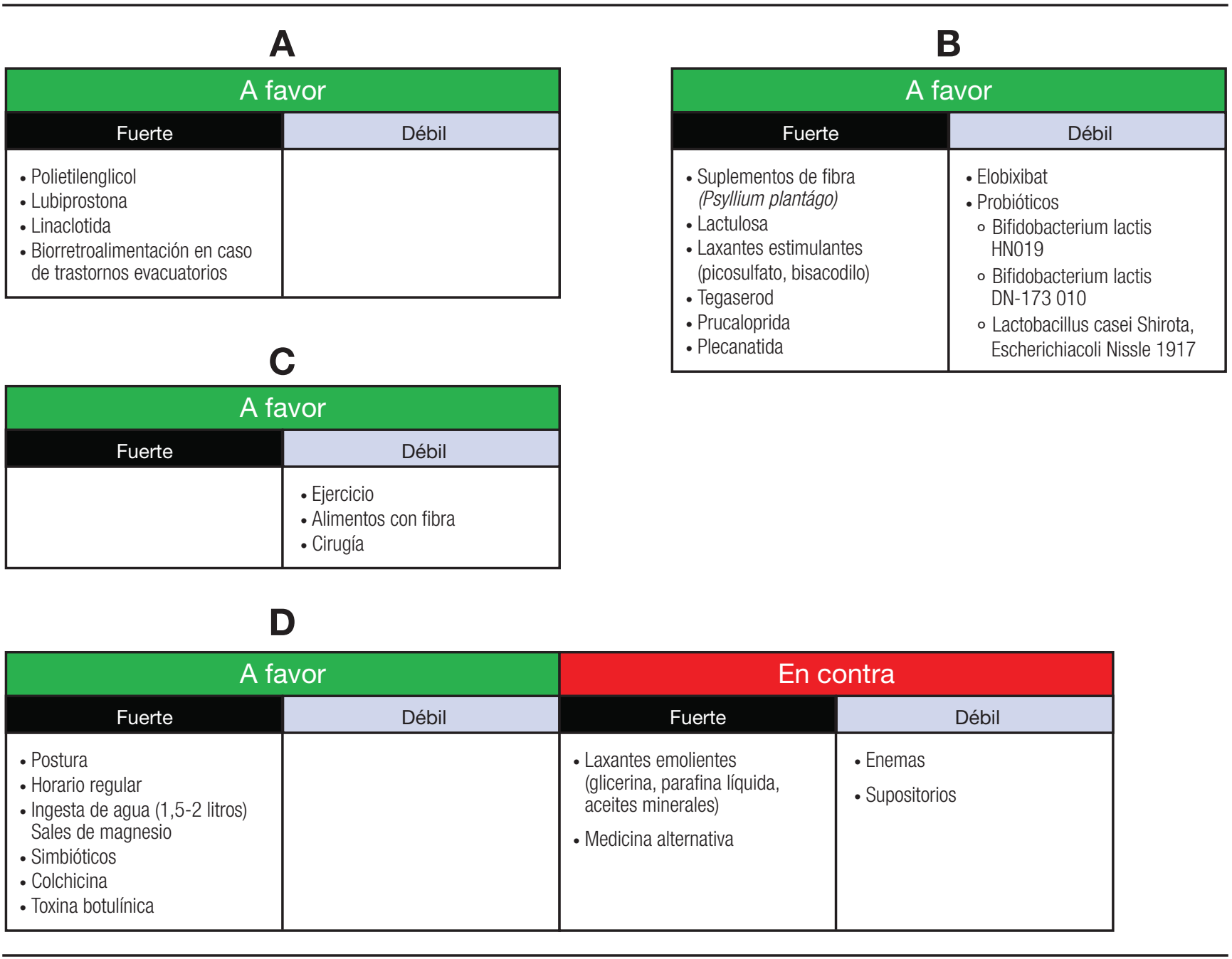

Nota: La calidad de la evidencia $\mathbf{A}$ se considera alta, la $\mathbf{B}$ moderada, la $\mathbf{C}$ baja y la $\mathbf{D}$ muy baja.

1. Laxantes osmóticos: Los laxantes son fármacos que alteran la composición de las heces o la motilidad gastrointestinal para aumentar la frecuencia de las heces o facilitar la defecación. ${ }^{1}$ Los agentes osmóticos incluyen soluciones a base de polietilenglicol (PEG), productos a base de citrato de magnesio, de fosfato de sodio y carbohidratos no absorbibles como la lactulosa. A través de la ósmosis, estos productos hipertónicos extraen líquido al lumen intestinal para ablandar las heces y acelerar el tránsito del colon. De acuerdo con la revisión de Cochrane de $2010,{ }^{74}$ el PEG es mejor que la lactulosa para aumentar la frecuencia de las evacuaciones, disminuir su consistencia y la necesidad de laxantes de rescate. Se ha estimado un número necesario a tratar (NNT) de 3. Los efectos secundarios reportados son poco frecuentes y los más comunes son dolor abdominal y cefalea. El NNT estimado para lactulosa es 4. Sin embargo, como se mencionó antes, en la revisión de Cochrane, PEG es superior a lactulosa. Debido a que la lactulosa no se absorbe sistémicamente, se considera un fármaco muy seguro en niños y en mujeres embarazadas, considerándose en este grupo de pacientes como el tratamiento de primera línea. ${ }^{75}$ Es importante destacar que la capacidad de fermentar en la luz colónica es responsable de efectos adversos como cólicos, flatulencias, dolor y distensión abdominal, que a veces son poco tolerables en algunos pacientes, lo que limita su uso.

2. Laxantes estimulantes: Los agentes como bisacodilo y picosulfato de sodio inducen contracciones colónicas propagadas. El bisacodilo y el picosulfato de sodio tienen efectos secretores y antiabsorbentes. ${ }^{1}$ Estos agentes pueden usarse como agentes de rescate (por ej., si los pacientes no tienen una evacuación intestinal durante 
2-3 días). Estudios recientes han mostrado que el picosulfato de sodio mejoró la consistencia y frecuencia de las heces, así como la facilidad de evacuación y la calidad de vida, en comparación con el placebo. ${ }^{76} \mathrm{El} \mathrm{NNT} \mathrm{con}$ el uso de bisacodilo y picosulfato se estima en $3 .{ }^{1}$ Los efectos secundarios más comunes de los difenilmetanos son dolor cólico, meteorismo y desequilibrio hidroelectrolítico, aunque también se han informado erupciones cutáneas, síndrome de Stevens-Johnson, reacciones parecidas al lupus y enteropatía con pérdida de proteínas. No existe evidencia para recomendar el uso de otros laxantes estimulantes como las antraquinonas (por ej senna, cáscara sagrada, hojas de sen) en pacientes con EF. Este grupo de medicamentos puede ser útil para el estreñimiento ocasional y por períodos cortos. Los efectos secundarios establecidos de este grupo de medicamentos son reacciones alérgicas, desequilibrio hidroelectrolítico y melanosis coli. La melanosis coli o pseudo-melanosis coli se debe al depósito de lipofuscina y otros pigmentos en los macrófagos. La mayor parte de los pacientes desarrollan tolerancia, lo que requiere aumentar la dosis de manera progresiva.

3. Secretagogos: Estos medicamentos estimulan la salida neta de iones y agua hacia la luz intestinal, mediante la activación de canales de cloro (lubiprostona) o activación de la guanilato ciclasa (linaclotida y plecanatida), lo que acelera el tránsito y facilita la defecación. ${ }^{1,77} \mathrm{Al}$ activar los canales en la superficie del enterocito apical, estos secretagogos aumentan la secreción intestinal de cloruro. Otros canales de iones y transportadores secretan sodio en el intestino para mantener la electroneutralidad, seguido de la secreción de agua. La lubiprostona es un ácido graso bicíclico derivado de la prostaglandina E1, que activa los canales de cloruro tipo 2 en la membrana apical de las células epiteliales. ${ }^{31}$ En el estudio pivote de Johanson y col. ${ }^{78}$ se demostró que a dosis de $24 \mu \mathrm{g}$ dos veces al día por cuatro semanas, la lubiprostona incrementa el número de evacuaciones espontáneas a la primera semana, en comparación con placebo (5,69 vs. $3,46, p=0,0001)$. Se estima que el NNT con lubiprostona es de $4 .{ }^{79}$ Los efectos adversos reportados, como náuseas, vómitos y diarrea, son comunes (incidencia variable de 2 a 75\%), pero la presencia de efectos adversos serios que obligan a la suspensión del fármaco son menores al 5\%. Se desconoce cuál es el mecanismo por el cual el fármaco produce náuseas y vómitos.

La linaclotida y la plecanatida son activadores de la guanilato ciclasa $\mathrm{C}$, que inducen la secreción de líquido hacia el tracto gastrointestinal a través de un aumento del monofosfato de guanosina cíclico y la activación posterior del regulador transmembrana de la fibrosis quística. La linaclotida en dosis de $145 \mu \mathrm{g}$ al día ha demostrado ser eficaz para alcanzar más de tres evacuaciones espontáneas completas por semana. ${ }^{80,81}$ Además, se ha demostrado que linaclotida mejora la consistencia de las evacuaciones, el esfuerzo para evacuar y otros síntomas asociados al estreñimiento, así como la calidad de vida. El NNT se estima en 6 . El evento adverso más común es la diarrea, que se presenta entre el 14-16\% comparado con 5\% con el placebo, pero la diarrea severa que lleve a suspensión del tratamiento se presenta en $4,8 \%$ de los casos. ${ }^{81}$

$\mathrm{Al}$ igual que la linaclotida, se ha descripto que la plecanatida tiene efectos antinociceptivos. ${ }^{82}$ Existe un ensayo fase III, multicéntrico, en el que se evaluó el efecto de 3 o $6 \mathrm{mg}$ de plecanatida durante doce semanas, comparado con placebo, en 1394 pacientes con EF. ${ }^{83}$ En este estudio se encontró que los pacientes que recibieron plecanatida (3 o $6 \mathrm{mg}$ ) tuvieron una mejor respuesta (> 3 evacuaciones espontáneas completas durante las doce semanas de tratamiento), comparado con placebo $(21 \%, 19,5 \%$ y $10,2 \%, p=0,001)$. El efecto adverso más común fue diarrea, en 5,9\% de los pacientes que recibieron $3 \mathrm{mg}, 5,7 \%$ de los que recibieron $6 \mathrm{mg}$ y 1,3\% en el grupo placebo.

4. Agonistas del receptor de serotonina

5HT-4: Al estimular los receptores de serotonina 5-HT4, distribuidos en las neuronas entéricas, los agonistas de 5-HT4 liberan acetilcolina e inducen la secreción mucosa. El tegaserod es un agonista selectivo de receptores de 5-HT4, sin actividad sobre receptores 5-HT3, que en múltiples ensayos clínicos demostró su eficacia en EF y SII-E. De acuerdo con la revisión de Cochrane en EF, ${ }^{84} \mathrm{el}$ RR de ser respondedor, considerando el número de evacuaciones por semana con $12 \mathrm{mg}$ de tegaserod, es de 1,54, comparado con 0,6 con el placebo. Aunque en marzo del 2007 la Administración de Drogas y Alimentos de los Estados Unidos restringió la comercialización del tegaserod debido al incremento de la incidencia de eventos cardiovasculares, recientemente se ha reconsiderado su uso y se ha restringido a pacientes sin riesgo cardiovascular (mujeres, menores de 55 años, sin hipertensión y sin hipercolesterolemia). ${ }^{85}$ La prucaloprida es un agonista del receptor 5-HT4, altamente selectivo, que activa la señalización de las neuronas aferentes y aumenta la motilidad intestinal. Fue aprobada en Europa para el tratamiento del estreñimiento crónico en mujeres en las que los laxantes no proporcionan un alivio adecuado. ${ }^{1}$ La prucaloprida es segura y no tiene efectos secundarios cardiovasculares. En un análisis de seguimiento de los tres estudios pivote, ${ }^{86-88}$ en los que se dejó tratamiento continuo (hasta 18 meses) a los pacientes que habían respondido durante doce semanas, se demostró que el $40-50 \%$ de los pacientes no tuvieron necesidad de consumir laxantes. ${ }^{89}$ Se estima que el 
NNT para prucaloprida es de 5. Los efectos adversos más comunes incluyen trastornos gastrointestinales (como diarrea, náuseas y dolor abdominal) y cefalea.

5. Prebióticos y probióticos: Algunas cepas específicas de probióticos (Bifidobacterium lactis DN173 010, Lactobacillus casei Shirota y Escherichia coli Nissle1917) y algunos simbióticos (múltiples cepas en combinación con fructooligosacáridos) parecen ser benéficos en EF, ya que aumentan la frecuencia de las evacuaciones y mejoran la consistencia de las heces. ${ }^{90-93}$ Aunque en los metaanálisis se muestra el beneficio de los probióticos y simbióticos en EC, todos enfatizan el alto riesgo de sesgo y la heterogeneidad, por lo que son cautelosos en sus recomendaciones.

6. Inhibidores del transportador de ácidos biliares: El elobixibat es un inhibidor del transportador ileal de ácidos biliares que tiene efectos secretores y motores a nivel colónico. ${ }^{94}$ Existen tres estudios que han evaluado el elobixibat en EF, que demostraron que es capaz de acelerar el tránsito intestinal, aumentar la frecuencia y disminuir la consistencia de las evacuaciones. ${ }^{95-97} \mathrm{El}$ efecto adverso más común reportado es la diarrea (2-13\%).

c) Terapia de biorretroalimentación: Esta se considera la terapia de elección para el tratamiento a corto y largo plazo de pacientes con estreñimiento y disinergia defecatoria. ${ }^{1}$ El número de sesiones varía, pero la mayoría de los centros incluyen los siguientes pasos en su protocolo: educación del paciente sobre la fuerza adecuada para la defecación, entrenamiento para mejorar la fuerza de empuje abdominal y para relajar los músculos del piso pélvico, y práctica de defecación simulada mediante el uso de la prueba de expulsión del balón. La terapia se lleva a cabo en cinco a seis sesiones de entrenamiento durante 30-60 minutos a intervalos de dos semanas. La habilidad y experiencia del terapeuta y la motivación del paciente influyen en la respuesta a la terapia de biorretroalimentación.

d) Tratamiento quirúrgico: El tratamiento quirúrgico debe ser limitado en pacientes que han fallado a la respuesta con tratamiento médico y biorretroalimentación, y en quienes se ha confirmado neuropatía colónica. ${ }^{1} \mathrm{La}$ colectomía abdominal y la anastomosis ileorrectal es una opción en estos pacientes. Las posibles complicaciones incluyen íleo, obstrucción del intestino delgado, fuga anastomótica e infecciones de la herida. Otros enfoques quirúrgicos o mínimamente invasivos para el estreñimiento con tránsito lento incluyen enemas colónicos anterógrados, que se administran mediante la infusión de agua en el colon ya sea a través de un conducto apendicular (procedimiento de Malone) o un catéter de cecostomía permanente (cecostomía endoscópica percutánea). ${ }^{31}$

\section{e) Otras terapias}

1. Trasplante de microbiota fecal: Recientemente se ha investigado el trasplante de microbiota fecal (FMT) como una posible estrategia para el manejo del EC. Un ensayo de sesenta individuos con estreñimiento de tránsito lento mostró que $37 \%$ de los sujetos lograron tener tres o más deposiciones espontáneas completas, en comparación con un 13\% de los pacientes que recibieron placebo. ${ }^{98}$ No obstante, el mecanismo de acción, los riesgos y la disponibilidad de esta terapia hacen que aún se considere experimental.

2. Cápsula vibratoria: La cápsula vibratoria es una nueva opción de tratamiento no farmacológico para el estreñimiento. Dos estudios han mostrado que la ingesta de este dispositivo dos veces por semana, durante y dentro de las tres horas posteriores al inicio de las vibraciones, resulta en un porcentaje significativamente mayor de evacuaciones intestinales espontáneas completas.99, 100 $\mathrm{Al}$ parecer, esta terapia puede mejorar el estreñimiento al aumentar los efectos fisiológicos del despertar y las comidas sobre las deposiciones y el ritmo circadiano. Al igual que el trasplante, se considera una terapia experimental.

\section{Conclusiones}

En la actualidad se reconoce que el EC es una entidad compleja y con múltiples mecanismos fisiopatológicos relacionados, lo que ha permitido un mejor abordaje clínico. Los avances en el diagnóstico y el tratamiento han logrado que existan múltiples opciones terapéuticas para brindar un mayor alivio de los síntomas y una mejor calidad de vida. Las medidas convencionales deben recomendarse para todos los pacientes, pero la selección del tratamiento farmacológico dependerá del subtipo del EC, la disponibilidad, el costo y la tolerancia del paciente a los nuevos fármacos.

\section{Aviso de derechos de autor}

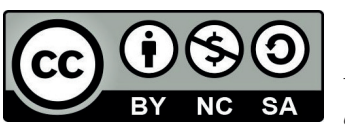

(c) 2021 Acta Gastroenterológica Latinoamericana. Este es un artículo de acceso abierto publicado bajo los términos de la Licencia Creative Commons Attribution (CC BY-NC-SA 4.0), la cual permite el uso, la distribución y la reproducción de forma no comercial, siempre que se cite al autor y la fuente original.

Cite este artículo como: García-Zermeño KR, RemesTroche JM. Constipación crónica. Conceptos actuales desde la fisiopatologia hasta el tratamiento. Acta Gastroenterol Latinoam. 2021;51(1):14-28. https://doi.org/10.52787/ zrrj9030 


\section{Referencias}

1. Remes-Troche JM, Coss-Adame E, Lopéz-Colombo A, et al. The Mexican consensus on chronic constipation. Rev Gastroenterol Mex. 2018;83(2):168-89.

2. Pare P, Ferrazzi S, Thompson WG, et al. An epidemiological survey of constipation in Canada: definitions, rates, demographics, and predictors of health care seeking. Am J Gastroenterol. 2001;96:3130-7.

3. Suares NC, Ford AC. Prevalence of, and risk factors for, chronic idiopathic constipation in the community: systematic review and meta-analysis. Am J Gastroenterol. 2011;106:1582-91.

4. Sperber AD, Bangdiwala SI, Drossman DA, et al. Gastroenterology. 2021;160(1):99-114.

5. Palsson O, Goode PS, Burgio KL, et al. Association of low dietary intake of fiber and liquids with constipation: evidence from the National Health and Nutrition Examination Survey (NHANES). Am J Gastroenterol. 2013;108(5):796-803.

6. Huang R, Ho S-Y, Lo W-S, Lam T-H. Physical activity and constipation in Hong Kongadolescents. PLoS ONE. 2014;9(2):e90193.

7. Iovino P, Chiarioni G, Bilancio G, et al. New onset of constipation during long-term physical inactivity: a proof-of-concept study on the immobility-induced bowel changes. PLoS One. 2013;8:e72608.

8. Oettlé GJ. Effect of moderate exercise on bowel habit. Gut. 1991;32:941-4.

9. Scott SM, Simrén M, Farmer AD, et al. Chronic constipation in adults: Contemporary perspectives and clinical challenges. 1: Epidemiology, diagnosis, clinical associations, pathophysiology and investigation. Neurogastroenterol Motil. 2020:e14050.

10. Serra J, Pohl D, Azpiroz F, et al. European society of neurogastroenterology and motility guidelines on functional constipation in adults. Neurogastroenterol Motil. 2020;32(2):e13762.

11. Rao SS, Rattanakovit K, Patcharatrakul T. Diagnosis and management of chronic constipation in adults. Nat Rev Gastroenterol Hepatol. 2016;13(5):295-305.

12. Lacy BE, Mearin F, Chang L, et al. Bowel disorders. Gastroenterology. 2016;150:1393-407.

13. Gaertner J, Siemens W, Camilleri M, et al. Definitions and outcome measures of clinical trials regarding opioid- induced constipation: a systematic review. J Clin Gastroenterol. 2015;49:9-16.

14. Kalso E, Edwards JE, Moore RA, et al. Opioids in chronic non-cancer pain: systematic review of efficacy and safety. Pain. 2004;112:372-80.

15. Chaussade S, Khayri A, Roche $\mathrm{H}$, et al. Determination of total and segmental colonic transit time in constipated patients. Results in 91 patients with a new simplified method. Dig Dis Sci. 1989;34:1168-72.

16. Chen JH, Yu Y, Yang Z, et al. Colonic motor patterns in patients with chronic constipation assessed by high resolution manometry. Sesión de carteles presentada en: DDW; 3-6 de mayo de 2014; Chicago, ILL.Sa2007.

17. Stivland T, Camilleri M, Vasallo M, et al. Scintigraphic measurements of regional gut transit in severe idiopathic constipation. Gastroenterology. 1991;101:107-15.

18. Tzavella K, Riepl RI, Klauser AG, et al. Decreased substance P levels in rectal biopsies from patients with slow transit constipation. Eur J Gastroenterol Hepatol. 1996;8:1207-11.

19. Cortesini C, Cianchi F, Infantino A, Lise M. Nitric oxide synthase and VIP distribution in enteric nervous system in idiopathic chronic constipation. Dig Dis Sci. 1995;40:2450-5.
20. He CL, Burgart L, Wang L, et al. Decreased interstitial cell of Cajal volume in patients with slow-transit constipation. Gastroenterology. 2000;118:14-21.

21. Zikos TA, Kamal AN, Neshatian L, et al. High prevalence of slow transit constipation in patients with gastroparesis. J Neurogastroenterol Motil. 2019;25:267-75.

22. Gladman MA, Scott SM, Chan CL, Williams NS, Lunniss PJ. Rectal hyposensitivity: prevalence and clinical impact in patients with intractable constipation and fecal incontinence. Dis Colon Rectum. 2003;46:238-46.

23. Lynch AC, Anthony A, Dobbs BR, Frizelle FA. Anorectal physiology following spinal cord injury. Spinal Cord. 2000;38:573-80.

24. Pannek J, Greving I, Tegenthoff M, et al. Urodynamic and recto manometric findings in patients with spinal cord injury. Neurourol Urodyn. 2001;20:95-103.

25. Goyal O, Bansal M, Sood A. Clinical and anorectal manometry profile of patients with functional constipation and constipation-predominant irritable bowel syndrome. Indian J Gastroenterol. 2019;38:211-9.

26. Camilleri M, Ford AC, Mawe GM, et al. Chronic constipation. Nat Rev Dis Primers. 2017;3:17095.

27. Preston DM, Lennard-Jones JE. Anismus in chronic constipation. Dig Dis Sci. 1985;30:413-8.

28. Rao SS, Welcher KD, Leistikow JS. Obstructive defecation: a failure of rectoanal coordination. Am J Gastroenterol. 1998;93:1042-50.

29. Rao SS, Bharucha AE, Chiarioni G, et al. Anorectal disorders Gastroenterology. 2016;150:1430-42.

30. Bharucha AE, Lacy BE. Mechanisms, Evaluation, and Management of Chronic Constipation. Gastroenterology. 2020;158(5):1232-49

31. Grossi U, Di Tanna GL, Heinrich H, Taylor SA, Knowles $\mathrm{CH}$, Scott SM. Systematic review with meta-analysis: defecography should be a first-line diagnostic modality in patients with refractory constipation. Aliment Pharmacol Ther. 2018;48:1186-201

32. Dimidi E, Christodoulides S, Scott SM, Whelan K. Mechanisms of action of probiotics and the gastrointestinal microbiota on gut motility and constipation. Adv Nutr. 2017;8:484-94.

33. Zhu L, Liu W, Alkhouri R, Baker RD, Bard JE, Quigley EM, et al. Structural changes in the gut microbiome of constipated patients. Physiol Genomics. 2014;46:679-86.

34. Khalif IL, Quigley EM, Konovitch EA, Maximova ID. Alterations in the colonic flora and intestinal permeability and evidence of immune activation in chronic constipation. Dig Liver Dis. 2005;37:838-49.

35. Wolf PG, Parthasarathy G, Chen J, et al. Assessing the colonic microbiome, hydrogenogenic and hydrogenotrophic genes, transit and breath methane in constipation. Neurogastroenterol Motil. 2017;29:1-9.

36. Attaluri A, Jackson M, Paulson J, Rao SSC. Methanogenic flora is associated with altered colonic transit but not stool characteristics in constipation without IBS. Am J Gastroenterol. 2010;105:1407-11.

37. Singh P, Duehren S, Katon J, et al. Breath methane does not correlate with constipation severity or bloating in patients with constipation. J Clin Gastroenterol. 2020;54:365-9.

38. Sallam H, McNearney TA, Chen JD. Systematic review: pathophysiology and management of gastrointestinal dysmotility in systemic sclerosis (scleroderma). Aliment Pharmacol Ther. 2006;23:691-712. 
39. Nelson AD, Mouchli MA, Valentin N, et al. Ehlers Danlos syndrome and gastrointestinal manifestations: a 20-year experience at Mayo Clinic. Neurogastroenterol Motil. 2015;27:1657-66.

40. Fikree A, Aziz Q, Ahmed M, Mohammed S, Knowles CH, Scott M. Joint hypermobility syndrome, rectal hyposensitivity and severe constipation in young nulliparous females. Gut. 2013;62(Suppl 1):A98.

41. Knowles CH, Farrugia G. Gastrointestinal neuromuscular pathology in chronic constipation. Best Pract Res Clin Gastroenterol. 2011;25:43-57.

42. Travagli RA, Browning KN, Camilleri M. Parkinson disease and the gut: new insights into pathogenesis and clinical relevance. Nat Rev Gastroenterol Hepatol. 2020;17(11):673-85.

43. Swash M, Snooks SJ, Henry MM. Unifying concept of pelvic floor disorders and incontinence. J R Soc Med. 1985;78:906-11.

44. Drossman DA, Leserman J, Nachman G, et al. Sexual and physical abuse in women with functional or organic gastrointestinal disorders. Ann Intern Med 1990;113:828-33.

45. Farnam A, Somi MH, Sarami F, Farhang S, Yasrebinia S. Personality factors and profiles in variants of irritable bowel syndrome. World J Gastroenterol. 2007;13:6414-8.

46. Tantiphlachiva K, Rao P, Attaluri A, Rao SS. Digital rectal examination is a useful tool for identifying patients with dyssynergia. Clin Gastroenterol Hepatol. 2010;8:955-60.

47. Talley NJ. How to do and interpret a rectal examination in gastroenterology. Am J Gastroenterol. 2008;103:820-2.

48. Degen LP, Phillips SF. How well does stool form reflect colonic transit? Gut. 1996;39:109-13.

49. O’Donnell LJ, Virjee J, Heaton KW. Detection of pseudodiarrhoea by simple clinical assessment of intestinal transit rate. $\mathrm{Br}$ Med J. 1990;300:439-40.

50. Lewis SJ, Heaton KW. Stool form scale as a useful guide to intestinal transit time. Scand J Gastroenterol. 1997;32:920-4.

51. Heaton KW, O’Donnell LJ. An office guide to whole-gut transit time. Patients 'recollection of their stool form. J Clin Gastroenterol. 1994;19:28-30.

52. Saad RJ, Rao SS, Koch KL, et al. Do stool form and frequency correlate with whole-gut and colonic transit? Results from a multicenter study in constipated individuals and healthy controls. Am J Gastroenterol. 2010;105:403-11.

53. Carrington EV, Scott SM, Bharucha A, et al. Expert consensus document: advances in the evaluation of anorectal function. Nat Rev Gastroenterol Hepatol. 2018;15:309-23.

54. Evans RC, Kamm MA, Hinton JM, Lennard-Jones JE. The normal range and a simple diagram for recording whole gut transit time. Int J Colorectal Dis. 1992;7:15-17.

55. Bonapace ES, Maurer AH, Davidoff S, Krevsky B, Fisher RS, Parkman HP. Whole gut transit scintigraphy in the clinical evaluation of patients with upper and lower gastrointestinal symptoms. Am J Gastroenterol. 2000;95:2838-47.

56. Rao SS, Camilleri M, Hasler WL, et al. Evaluation of gastrointestinal transit in clinical practice: position paper of the American and European Neurogastroenterology and Motility Societies. Neurogastroenterol Motil. 2011;23(1):8-23.

57. Singh S, Heady S, Coss-Adame E, Rao SS. Clinical utility of colonic manometry in slow transit constipation. Neurogastroenterol Motil. 2013;25:487-95.

58. Pritchard SE, Paul J, Major G, et al. Assessment of motion of colonic contents in the human colon using MRI tagging. Neurogastroenterol Motil. 2017;29:e13091.
59. Chiarioni G, Whitehead WE. Anorectal physiology in health: A randomized trial to determine the optimum catheter for the balloon expulsion test. Neurogastroenterol Motil. 201931(7):e13582.

60. Chiarioni G, Kim SM, Vantini I, Whitehead WE . Validation of the balloon evacuation test: reproducibility and agreement with findings from anorectal manometry and electromyography. Clin Gastroenterol Hepatol. 2014;12:2049-54.

61. Rao SS, Azpiroz F, Diamant N, et al. Minimum standards of anorectal manometry. Neurogastroenterol Motil. 2002;14:553-9.

62. Carrington EV, Heinrich $\mathrm{H}$, Knowles $\mathrm{CH}$, et al. The international anorectal physiology working group (IAPWG) recommendations: standardized testing protocol and the London classification for disorders of anorectal function. Neurogastroenterol Motil. 2020;32:e13679.

63. Carrington EV, Brokjaer A, Craven H, et al. Traditional measures of normal anal sphincter function using high-resolution anorectalmanometry (HRAM) in 115 healthy volunteers. Neurogastroenterol Motil. 2014;26:625-35.

64. Coss-Adame E, Rao SS, Valestin J, et al. Accuracy and Reproducibility of High-definition AnorectalManometry and Pressure Topography Analyses in Healthy Subjects. Clin Gastroenterol Hepatol. 2015;13:1143-50.

65. Raizada V, Bhargava V, Karsten A, Mittal RK. Functional morphology of anal sphincter complex unveiled by high definition anal manometry and three-dimensional ultrasound imaging. Neurogastroenterol Motil. 2011;23:1013-9.

66. Gregersen H, Chen SC, Leung WW, et al. Novel fecobionics defecatory function testing. Clin Transl Gastroenterol. 2019;10:e00108

67. De Schryver AM, Keulemans YC, Peters HP, et al. Effects of regular physical activity on defecation pattern in middleaged patients complaining of chronic constipation. Scand J Gastroenterol. 2005; $40: 4229$.

68. Koffler KH, Menkes A, Redmond RA, et al. Strength training accelerates gastrointestinal transit in middle-aged and older men. Med Sci Sports Exerc. 1992;24:415-9.

69. Palit S, Lunniss PJ, Scott SM. The physiology of human defecation. Dig Dis Sci. 2012;57:1445-64.

70. Anti M, Pignataro G, Armuzzi A, et al. Water supplementation enhances the effect of highfiber diet on stoolfrequency and laxative consumption in adult patients with functional constipation. Hepatogastroenterology. 1998;45:72732.

71. Brownlee IA. The physiological roles of dietary fibre. Food Hydrocolloids. 2011;25:238-50.

72. McRorie J, Pepple S, Rudolph C. Effects of fiber laxatives and calcium docusate on regional water content and viscosity of digestion in the large intestine of the pig. Dig Dis Sci. 1998;43:738-45.

73. Christodoulides S, Dimidi E, Fragkos KC, Farmer AD, Whelan K, Scott SM. Systematic review with meta-analysis: effect of fibre supplementation on chronic idiopathic constipation in adults. Aliment Pharmacol Ther. 2016;44:103-16.

74. Lee-Robichaud H, Thomas K, Morgan J, Nelson RL. Lactulose versus polyethyleneglycol for chronic constipation. Cochrane Database Syst Rev. 2010;7:CD007570.

75. Carulli N, Salvioli GF, Manenti F. Absorption of lactulose in man. Digestion 1972;6:139-45.

76. Mueller-Lissner S, Kamm MA, Wald A, et al. Multicenter, 4-week, double-blind, randomized, placebo-controlled trial of sodium picosulfate in patients with chronic constipation. Am J Gastroenterol. 2010;105(4):897-903. 
77. Black CJ, Burr NE, Quigley EMM, Moayyedi P, Houghton LA, Ford AC. Efficacy of Secretagogues in Patients With Irritable Bowel Syndrome With Constipation: Systematic Review and Network Meta-analysis. Gastroenterology. 2018;155(6):1753-63.

78. Johanson JF, Morton D, Geenen J, Ueno R. Multicenter, 4-week, double-blind, randomized, placebo-controlled trial of lubiprostone, a locally-acting type- 2 chloride channel activator, in patients with chronic constipation. Am J Gastroenterol. 2008;103:170-7.

79. Ford AC, Suares NC. Effect of laxatives and pharmacological therapies in chronic idiopathic constipation: systematic review and meta-analysis. Gut. 2011;60:209-18.

80. Videlock EJ, Cheng V, Cremonini P. Effects of linaclotide in patients with irritable bowel syndrome with constipation or chronic constipation: a meta-analysis. Clin Gastroenterol Hep. 2013;11:1084-92.

81. Lembo AJ, Schneier HA, Shiff SJ, et al. Two randomized trials of linaclotide for chronic constipation. $N$ Engl J Med. 2011;365:527-36.

82. Brierley SM. Guanylatecyclase-C receptor activation: unexpected biology. Curr Opin Pharmacol. 2012;12:632-40.

83. Miner PB Jr, Koltun WD, Wiener GJ, De La Portilla M, Prieto B, Shailubhai K, Layton MB, Barrow L, Magnus L, Griffin PH. A Randomized Phase III Clinical Trial of Plecanatide, a Uroguanylin Analog, in Patients With Chronic Idiopathic Constipation. Am J Gastroenterol. 2017;112(4):613-621.

84. Evans BW, Clark WK, Moore DJ, Whorwell PJ. Tegaserod for the treatment of irritable bowel syndrome and chronic constipation (Review).Cochrane Database of Systematic Reviews. 2007;4:CD003960.

85. Quigley EMM, Wald A, Fidelholtz J, et al. Safety and tolerability of tegaserod in patients with chronic constipation: pooled data from two phase III studies. Clin Gastroenterol Hepatol. 2006;4:605-13.

86. Camilleri M, Kerstens R, Rykx A, Vandeplassche L. A placebo-controlled trial of prucalopride for severe chronic constipation. N Engl J Med. 2008;29:358.

87. Tack J, van Outryve M, Beyens G, Kerstens R, Vandeplassche L. Prucalopride (Resolor) in the treatment of severechronic constipation in patients dissatisfiedwith laxatives. Gut. 2009;58:357-65.

88. Quigley EM, Vandeplassche L, KerstensR, Ausma J. Clinical trial: the efficacy,impact on quality of life, and safety andtolerability of prucalopride in severechronic constipation - a 12-week, randomized, double-blind, placebo controlled study. Aliment Pharmacol Ther. 2009;29:315-28.

89. Camilleri M, Van Outryve MJ, Beyens G, Kerstens R, Robinson P, Vandeplassche L. Clinical trial: the efficacy of open-label prucalopride treatment in patients with chronic constipation - follow-up of patientsfrom the pivotal studies. Aliment Pharmacol Ther 2010;32:1113-23.
90. Dimidi E, Christodoulides S, Fragkos KC, Scott SM, Whelan K. The effect of probiotics on functional constipation in adults: a systematic review and meta-analysis of randomized controlled trials. The American journal of clinical nutrition. 2014;100(4):1075-84.

91. Chmielewska A, Szajewska H. Systematic review of randomised controlled trials: probiotics for functional constipation. World Journal of Gastroenterology. 2010;16(1):69-75.

92. Waitzberg DL, Logullo LC, Bittencourt AF, et al. Effect of symbiotic inconstipated adult women - a randomized, double-blind, placebo-controlledstudy of clinical response. Clin Nutr 2013;32:27-33.

93. Fateh R, Iravani S, Frootan M, et al. Synbiotic preparation in men sufferingfrom functional constipation: a randomized controlled trial. Swiss Med Wkly. 2011;141:w13239.

94. Gillberg PG, Dahlstr M, Starke I, et al. The IBAT inhibition by A3309 - apotential mechanism for the treatment of constipation. Gastroenterology. 2010;5(Suppl 1):224.

95. Simrén M, Bajor A, Gillberg PG, Rudling M, Abrahamsson H. Randomised clinical trial: the ileal bile acid transporterinhibitor A3309 vs. placebo in patients with chronicidiopathic constipation - a double-blind study. Aliment Pharmacol Ther 2011;34:41-50.

96. Chey WD, Camilleri M, Chang L, Rikner L, Graffner H. A randomized placebo-controlled phase IIB trial of A3309, a bile acid transporter inhibitor, for chronic idiopathic constipation. Am J Gastroenterol. 2011;106:1803-12.

97. Wong BS, Camilleri C. Effects of a3309, an ileal bile acid transporterinhibitor, on colonic transit and symptoms infemales with functional constipation. Am J Gastroenterol. 2011;106:2154-64.

98. El-Salhy M, Hatlebakk JG, Gilja OH, BrathenKristoffersen A, Hausken T. Efficacy of faecal microbiota transplantation for patients with irritable bowel syndrome in a randomised, doubleblind, placebo-controlled study. Gut. 2020;69:859-67.

99. Rao SSC, Lembo A, Chey WD, Friedenberg K, Quigley EMM. Effects of the vibrating capsule on colonic circadian rhythm and bowel symptoms in chronic idiopathic constipation. Neurogastroenterol Motil. 2020;32(11):e13890.

100. Nelson AD, Camilleri M, Acosta A, et al. A single-center, prospective, double-blind, sham-controlled, randomized study of the effect of a vibrating capsule on colonic transit in patients with chronic constipation. Neurogastroenterol Motil. 2017;29(7):e13034 10.1111/13034 